\title{
Fluid Bed Granulation
}

National Cancer Institute

\section{Source}

National Cancer Institute. Fluid Bed Granulation. NCI Thesaurus. Code C113008.

The process of forming granules involving the addition of liquid to bind particles as they are suspended in a fluidized state by a flowing gas stream, resulting in dry granules suitable for filling or compression. 